\title{
вмј Global Health Saving sight in China and beyond: the Lifeline Express model
}

\author{
Ian Yat Hin Wong, ${ }^{1}$ Michael Yuxuan Ni, ${ }^{2}$ Irene Oi Ling Wong, ${ }^{2}$ Nellie Fong, ${ }^{3,4}$ \\ Gabriel M Leung ${ }^{2}$
}

To cite: Wong IYH, Ni MY, Wong IOL, et al. Saving sight in China and beyond: the Lifeline Express model. BMJ Glob Health 2018;3:e000766. doi:10.1136/ bmjgh-2018-000766

Handling editor Seye Abimbola

- Additional material is published online only. To view please visit the journal online (http://dx.doi.org/10.1136/ bmjgh-2018-000766).

Received 12 February 2018 Revised 28 June 2018 Accepted 29 June 2018

Check for updates

(c) Author(s) (or their employer(s)) 2018. Re-use permitted under CC BY-NC. No commercial re-use. See rights and permissions. Published by BMJ.

${ }^{1}$ Department of Ophthalmology, Li Ka Shing Faculty of Medicine, The University of Hong Kong, Hong Kong, China

${ }^{2}$ School of Public Health, Li Ka Shing Faculty of Medicine, The University of Hong Kong, Hong Kong, China

${ }^{3}$ Lifeline Express, Lifeline Express Hong Kong Foundation, Hong Kong, China

${ }^{4}$ Chinese Foundation for Lifeline Express, Beijing, China

Correspondence to Dr Michael Yuxuan Ni; nimy@hku.hk

\section{ABSTRACT}

Cataract and diabetic retinopathy are leading causes of blindness globally. Lifeline Express (LEX) has pioneered the provision of cataract surgery in rural China from custom-built trains and eye centres nationwide. Over the past two decades, LEX has provided free cataract surgery for over 180000 patients in China. In China, half of the adult population has prediabetes and 113 million adults have diabetes. Recognising the rising threat of diabetic retinopathy, LEX has expanded to providing free diabetic retinopathy screening nationwide by establishing 29 Diabetic Retinopathy Screening Centres across China. Source of referrals included host hospitals, the community and out-reach mobile vans equipped with fundus cameras. Fundi photos taken in the mobile vans were electronically transferred to primary graders. LEX also leveraged the widespread smartphone use to provide electronic medical reports via WeChat, the most popular instant messenger app in China. From April 2014 to December 2016, 34506 patients with diabetes underwent screening, of which $27.2 \%(9,396)$ were identified to have diabetic retinopathy. China's latest national health strategy ('Healthy China 2030 Plan') has championed the 'prevention first' principle and early screening of chronic diseases. LEX has accordingly evolved to extend its services to save sight in China - from cataract surgery to diabetic retinopathy screening and most recently outreaching beyond its national borders in a pilot South-South collaboration. With health at the top of the China's developmental agenda and the country's growing role in global health-LEX's largescale telemedicine-enabled programme could represent a potentially scalable model for nationwide diabetic retinopathy screening elsewhere.

\section{INTRODUCTION}

Lifeline Express (LEX) comprises a Hong Kong-based charity established in 1997, the year the Special Administrative Region repatriated to China, and a Beijing-based charity established in 2002, with a mission to fight blindness in mainland China. Recognising cataract as the major treatable cause of blindness, LEX pioneered the provision of free cataract surgery in rural China from four custombuilt trains that are specially equipped with operating theatres. As would be anticipated, the programme had a difficult gestation and was initially met with concern from various
Summary box

- Lifeline Express is one of the leading charity organisations in providing free cataract surgery in China with services provided to over 180000 patients since 1997.

- China has around 100 million individuals with diabetes; however, many of these patients do not receive annual diabetic retinopathy screening.

- Lifeline Express has accordingly established a largescale nationwide diabetic retinopathy screening program in China, which is telemedicine enabled, free and of international standards. To date, the Lifeline Express diabetic retinopathy screening program has set up 29 centres throughout China and has screened over 34000 patients.

- Lifeline Express has evolved to needs, nationally and globally, from cataract surgery to diabetic retinopathy screening to global health in line with the Belt and Road Initiative- -with Sri Lanka the first among countries beyond China which Lifeline Express has extended its services to save and give sight nationally and globally.

local hospitals along the planned train routes as well as much scepticism from potential patients. However, successful stories of sight restoration soon spread, and extensive negotiations with local stakeholders and government officials eventually led to the now virtually universal acceptance of LEX throughout the country, from the highest levels of government to patients at the grass roots. In addition to the trains, LEX has set up 69 eye centres nationwide to provide training for cataract surgeons. These centres were established within existing medical facilities, such as a major provincial or county hospital, which are usually secondary or tertiary referral centres within a province (figure 1). This provides a safety net for complex cases and offers comprehensive training for young ophthalmologists in the formative stages of training. Over the past 20 years, LEX has provided free cataract surgery for over 180000 patients in China and has established the charity as a leading national provider of cataract surgery. 

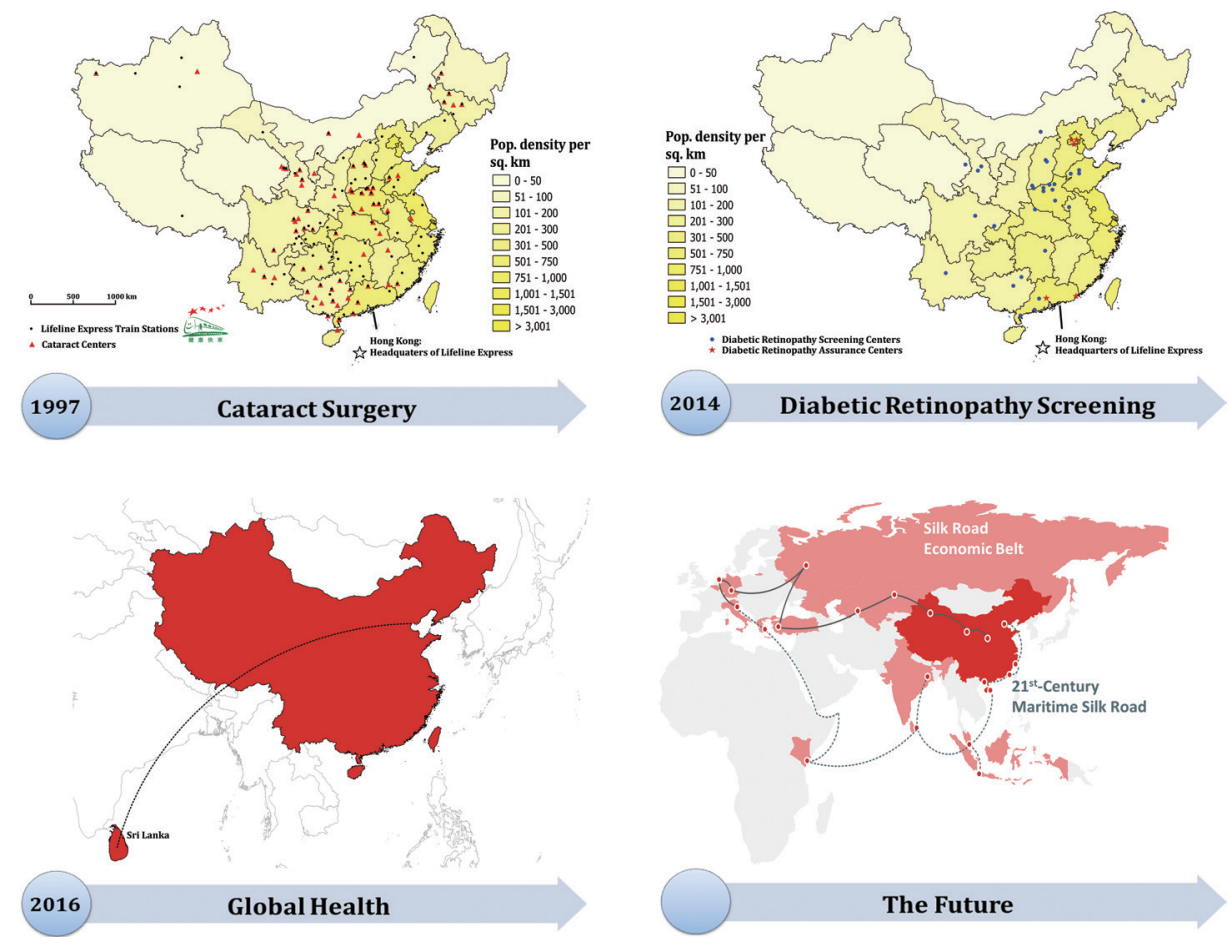

Figure 1 Evolution of Lifeline Express's service portfolio.

Riding on the success in saving sight through providing free cataract surgery, since 2014, LEX has expanded to providing free diabetic retinopathy (DR) screening nationwide (figure 1). The estimated prevalence of diabetes mellitus and prediabetes among adults in China is $10.9 \%$ and $35.7 \%$, respectively-which translates into around 110 million Chinese adults with diabetes and 388 million individuals with prediabetes. ${ }^{1}$ DR is a major cause of morbidity in patients with diabetes and is a leading cause of blindness in the developed world. ${ }^{23}$ Even with treatment, many patients still suffer significant visual loss. ${ }^{45}$ Early detection through screening could potentially save sight. ${ }^{6-11}$ However, regular screening for more than 100 million individuals would be a formidable challenge to any healthcare system.

With the 'reform and opening up' of the Chinese economy since 1978, its health system became increasingly unsustainable with rising costs and uneven coverage. ${ }^{12}$ Therefore, after a series of incremental changes, China decided to launch a major set of health system reforms in 2009, committing to comprehensive universal health coverage by $2020 .^{13}$ By 2012, the Chinese government completed the introduction of a subsidised insurance system that provides $95 \%$ of the population with modest health coverage and set out to establish a primary care system. ${ }^{14}$ However, opportunistic, haphazard DR screening programmes are currently offered in a dozen or so major Chinese cities. Moreover, there are approximately 28000 ophthalmologists in China. This is the equivalent of 20 ophthalmologists per 1 million people, whereas the corresponding figures in the UK and USA are 49 and 59 per 1 million, respectively. ${ }^{16}$ Inadequate manpower, the lack of financial incentives in the social insurance provider payment system and absent infrastructure have precluded the implementation of nationally based DR screening thus far.

LEX therefore seized the opportunity to rise to this substantial challenge of DR screening, building on its demonstrated success with the national cataract surgery programme. LEX, being headquartered in Hong Kong, took full advantage of its base as an epidemiologic and healthcare sentinel for the rest of the country and adapted the city's experience with its public sector DR screening program ${ }^{9}$ in developing a national model.

Here we report how LEX, China's leading charity cataract surgery provider, has expanded its scope of sightsaving portfolio of work by providing free DR screening and most recently outreaching beyond its national borders in a pilot South-South collaboration.

\section{ESTABLISHING A NATIONAL MODEL FOR DR SCREENING}

Since 2014, eye centres have been progressively expanded to host a Diabetic Retinopathy Screening Centre (DRSC). In addition, independent DRSCs have also been established. To date, there are a total of 29 DRSC across China (figure 1). The DRSCs are situated in 15 out of 28 provinces and autonomous regions of China, and each centre has a staff ophthalmologist serving as primary grader (PG) for DR screening.

The main source of referrals is from host hospitals of the DRSCs (figure 2). The PGs at each DRSC work closely with physicians and endocrinologists to offer annual screening to all patients with diabetes. The screening programme is also promoted in the local community through regular health talks and posters to reach 


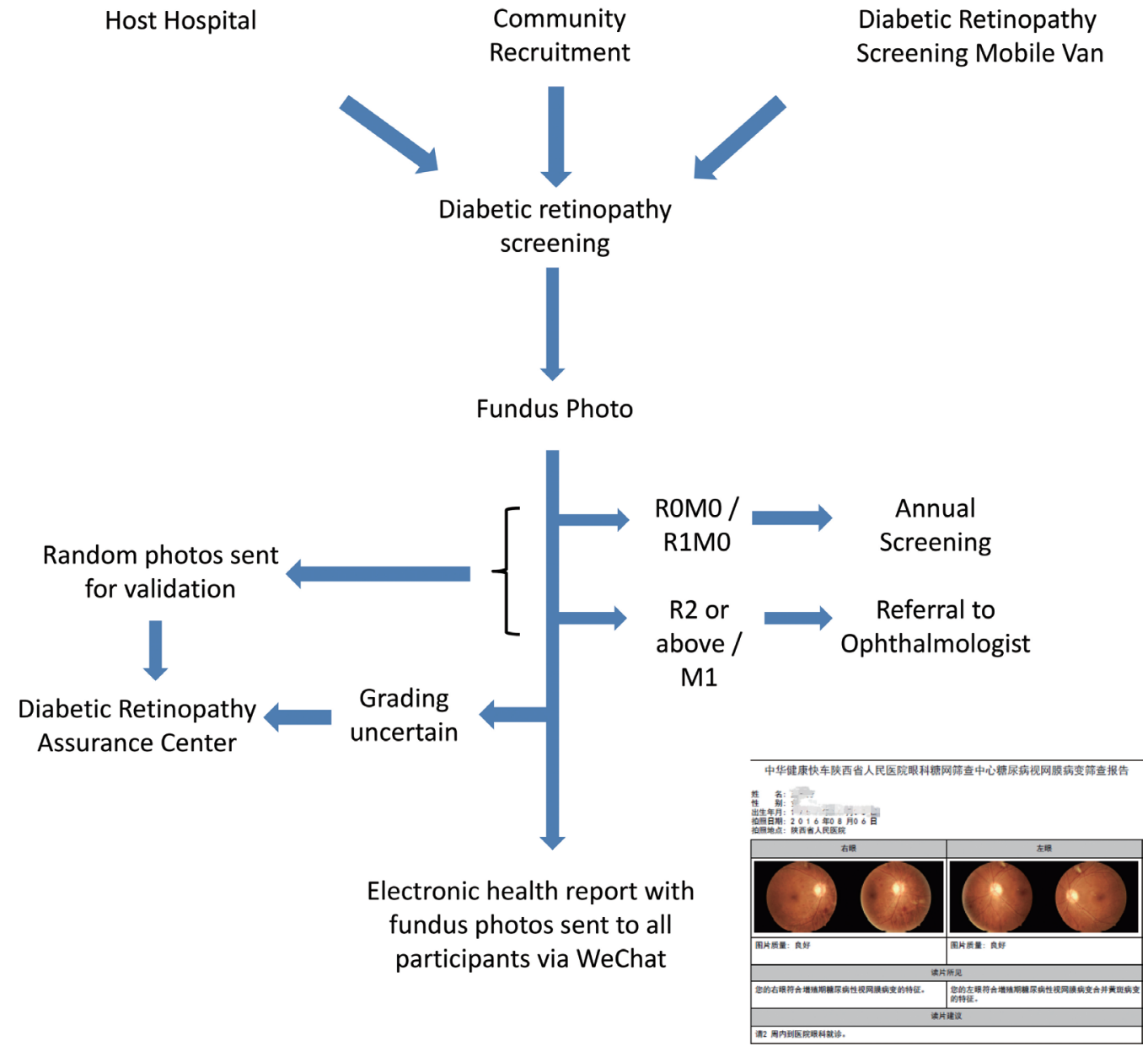

Figure 2 Flow chart of diabetic retinopathy screening.

patients who may not already be receiving care in the host hospitals. A further source of patients is the Diabetic Retinopathy Screening Mobile Van (DRMV), a customised van with a fundus camera that is staffed by a trained team. The DRMVs would organise trips to nearby cities and villages, such that patients with diabetes residing in more remote areas would have access to DR screening. Fundi photos taken in the DRMV are electronically transferred to one of the five 'Diabetic Retinopathy Assurance Centres' (DRACs) for immediate grading.

\section{INFRASTRUCTURE AND WORKFLOW}

All individuals with diabetes, regardless of duration and severity, are offered annual DR screening at the DRSCs free of charge. This includes fundus photos, which are taken by nurses or technicians, and are graded by the PGs immediately per international grading classifications (online Supplementary table 1). ${ }^{17}$ Undilated fundus photography using non-mydriatic fundus cameras with at least 45 degrees view of the macular was used. Two pictures are taken from each eye, that is, one centred at the fovea and the other centred at the disc. Around 15\% of all images taken were considered ungradable. Reasons for ungradable images included media opacities, such as cataract or vitreous haemorrhage, or the patient's inability to adhere to procedure. Images would be retaken on site with pupil dilation. If the image remains ungradable, patients would be referred to ophthalmologists. Those with no or mild abnormalities, that is, R0M0 or R1M0, are advised to return for screening 1 year later. Individuals found to have sight-threatening DR (ie, R2 or above or M1) are referred to ophthalmologists for further assessment as per established guidelines. ${ }^{917}$

A medical report with the diagnosis and fundus photos are provided to patients within 2 hours via a mobile app installed on their cellular phones (figure 2). The mobile app is an add-on to WeChat (also known as Weixin), the most popular instant messenger app in China. Patients having referable grading are recommended to attend the affiliated ophthalmology clinic in the host hospital. Host hospitals are often major hospitals with expertise in handling DR and related complications. Patients usually pay out-of-pocket to host hospitals for consultations and subsequent procedures.

\section{QUALITY ASSURANCE}

LEX pays for all PGs to complete a 6 month online DR screening certification programme provided by the University of Gloucestershire in UK. When PGs are unable to grade a fundus photo, that is, when the two 
PGs disagree on the grading on a particular set of photos, second-tier graders at one of the DRACs would provide arbitration.

\section{PRELIMINARY EVALUATION}

So far, a total of 34506 patients with diabetes were screened from 2014 to December 2016 at the 29 DRSCs (online Supplementary table 2). Among these, 9396 $(27.2 \%)$ were screened to have DR. The prevalence of R3 was $3.1 \%(\mathrm{n}=1075)$, R2 was $3.1 \%(\mathrm{n}=1069), \mathrm{R} 1$ was $21.0 \%(\mathrm{n}=7252)$ and M1 (regardless of $\mathrm{R}$ status) was $10.0 \%(\mathrm{n}=3460)$. When compared with the DR screening programme in Hong Kong and Wales, the prevalence of sight-threatening DR (ie, R2 or above, or M1) was found to be substantially higher (LEX DR screening programme R2: 3.1\%, R3: 3.1\%, M1: 10.0\%; Hong Kong R2: $3.0 \%$, R3: 0.3\%, M1: 8.6\%; Wales R2: 1.5\%, R3: 0.3\%, M1: $1.4 \%) .{ }^{910}$ The higher prevalence of more severe DR (ie, R2, R3 and M1) found in the LEX programme might be due to the sampling frame and the absence of systematic DR screening in China, which may have contributed to progression in DR.

Comprehensive disease registries such as on diabetes are often lacking in low-income and middle-income countries and even the coverage of vital statistics is less than half of the population in China. ${ }^{18}$ We have therefore focused on a case study as an example of the local circumstances. Mianzhu is a county-level city in the Province of Sichuan that was heavily affected by the 2008 Sichuan earthquake. Mianzhu has a population of around 505 000, including 16043 individuals with diabetes. To date, Lifeline Express has provided DR screening for 4018 residents in Mianzhu. The city's host hospital is the People's Hospital of Mianzhu, where there are currently six ophthalmologists, of which one ophthalmologist has experience in treating diabetic eye diseases. Complicated cases are referred to the People's Hospital of Deyang based in a larger prefecture-level city. Among the 4018 patients screened in Mianzhu, $396(9.9 \%)$ were found to have sight-threatening DR and thus were referred to ophthalmologists for further management. One-third $(n=132)$ of those screened positive subsequently received treatment at the host hospital. The remaining either sought treatment elsewhere or defaulted. The proportion of those screened positive that have received treatment is comparable to other screening programmes. ${ }^{19-21}$

Monitoring data is needed for the continuous evaluation of health services including the coverage of the programme, the proportion of those screened positive that return for annual screening, the proportion of those screened positive or with unreadable images that receive confirmatory diagnosis and treatment and clinical audits. Large cohort studies have been established in China and elsewhere, which could be leveraged by nesting screening services within these surveys. This would allow the identification of baseline predictors for uptake of screening and subsequent treatment and thereby inform targeted interventions.

\section{EXPANSION OF FRAMEWORK BEYOND CHINA}

In 2013, China launched the Belt and Road Initiative to connect the Asian-Pacific Economic Area with Africa and Europe, which has been referred to as the 21st century Silk Road. This initiative will play a central role in China's global health strategy $y^{223}$ and could promote regional and international cooperation to improve health outcomes, particularly in middle-income and low-income nations. ${ }^{24}$ An implementation plan to promote the development of health and safeguard health security as part of the Belt and Road Initiative was issued by the China's National Health and Family Planning Commission. ${ }^{25} 26$

In accordance with China's global health strategy, LEX has planned to extend its model along the New Silk Road. In collaboration with the Ministry of Foreign Affairs, LEX supported an ophthalmic medical team from Beijing for a 4-week mission to save sight in Sri Lanka. The team aims to establish a cataract surgery network using the LEX model in Sri Lanka. Thus far, more than 500 individuals in the city of Kalutara have received free cataract surgeries. In the footsteps of the China model, DRSCs could be added to the cataract network in the next stage. LEX is currently working with other middle-income and low-income countries such as Pakistan and Myanmar to set up similar models to save sight.

\section{CHALLENGES AND LESSONS LEARNT}

The primary challenge for LEX is to develop a sustainable model for annual DR screening in China such that case finding is continuous. In the interim results, the prevalence of R3 and M1 cases detected were higher than that in other populations where a systematic DR screening programme exists. ${ }^{8}{ }^{27-29}$ However, volunteer bias would suggest that these figures are not generalisable to the rest of China. Nevertheless, with more than 100 million individuals with diabetes in China-there is a need for a nationwide DR screening programme. A concerted effort to improve detection of diabetes would be needed given the prevalence of undiagnosed diabetes in China to be $8.5 \% .^{30}$

In line with the Wilson and Jungner criteria, the LEX model provides facilities for diagnosis and treatment ${ }^{31}$ by nesting DRSCs in major provincial hospitals that have the capacity to manage complex cases. However, accessibility of these facilities for those screened positive but cannot afford downstream medical care would need to be addressed. While revenue generated by management of these referrals incentivises hospitals to host DRSCsformal economic evaluation would be required to determine the cost-effectiveness of this programme. LEX has allocated on average $120000 \mathrm{RMB}$ (equivalent to US $\$ 19000$ ) per annum for each DRSC to cover the cost of fundus photography, training and software. Funding is mainly from donations. 
The number of internet users in China has been estimated to be at 751 million in 2017 , and $96.3 \%$ accessed the internet on their smartphones. ${ }^{32}$ The LEX DR programme took advantage of this by providing electronic medical reports via smartphone in line with China's national strategy of promoting technological innovation. ${ }^{33}$ This allows attending ophthalmologists to assess fundus photos on the patient's smartphone as well as their health reports. The next step would be to integrate the DR electronic report with electronic health records in the host hospital.

\section{CONCLUSION}

With half of China's adult population estimated to be having prediabetes, implementation of a nationwide strategy for DR screening is urgently needed. ${ }^{30}$ This would address the 'prevention first' principle championed by the 'Healthy China 2030 Plan'. ${ }^{33}$ The latest national health strategy has accordingly prioritised early screening of chronic diseases as well as intervention programmes for diabetes. ${ }^{33}$ LEX should therefore work with national drivers and local stakeholders to expand its existing network of DRSCs and obtain funding. With China's strategic target of expanding health service delivery capacity via the establishment of healthcare systems, ${ }^{33}$ DR screening and other sight-saving services should be incorporated into these new integrated healthcare systems.

With the DR grading support from DRACs via telemedicine and support from host hospitals for management of difficult cases, this represents a potentially scalable model for a nationwide DR screening programme. This would require in tandem an expansion in DRSCs and DRACs. To enhance the capacity to manage complex cases identified from screening, LEX continues to support experts from Hong Kong and overseas (including the UK, USA, Australia and Germany) to visit the DRSCs to provide supervision and training for the local ophthalmologists.

Prevention for DR-related visual loss also requires health education, health promotion, good glycaemic and blood pressure control to complement screening programmes. ${ }^{34}$ DRSC may therefore partner with clinicians in host hospitals as well as public health agencies to provide both population-based strategies and interventions for highrisk individuals for the prevention of diabetes and related complications. Diabetic retinopathy is a health issue of global concern and of great relevance to high-income, middle-income and low-income settings. LEX's nationwide telemedicine-enabled diabetic retinopathy screening programme may therefore be of considerable interest to policymakers in other large, middle-income countries.

LEX has continuously evolved to extend its services to save sight in China and changing its model to fit the purpose at hand-from cataract surgery to DR screening and more recently contributing to global health beyond its own borders. With Sri Lanka as the first step beyond China, LEX is looking into expanding its coverage to populations beyond its borders. With health at the top of the China's developmental agenda and the country's growing role in global health ${ }^{33}$ - LEX is dedicated to making the DR screening programme sustainable and looks forward to the future as its role continue to evolve to needs, nationally and globally.

Acknowledgements We thank Professor Jimmy Lai for his invaluable advice, Mingyue Wang and Lu Ya for their assistance in gathering data and Betty Yuan for her technical assistance. The Lifeline Express is an independent charitable organisation and would like to acknowledge the following donors: Li Ka Shing Foundation, Hutchison Whampoa Limited, The Fred Hollows Foundation, China Guodian Corporation, China State Construction Engineering Corporation and the China National Pharmaceutical Group Corporation. The Lifeline Express would like to acknowledge the following centers for their contribution in the Diabetic Retinopathy Screening Program (alphabetical order): Baiyin First People's Hospital, Baiyin, Gansu Province; Chuxiong People's Hospital, Chuxiong, Yunnan Province; Danjiangkou First Hospital, Danjiangkou, Hubei Province; Fuyang First People's Hospital, Fuyang, Anhui Province; Guang'an People's Hospital, Guang'an, Sichuan Province; Guilin No. 2 People's Hospital, Guilin, Guangxi Province; Haidong People's Hospital, Haidong, Qinghai Province; Inner Mongolia People's Hospital, Hohhot, Inner Mongolia Autonomous Region; Jiaozuo Eye \& ENT Hospital, Jiaozuo, Henan Province; Jilin Hospital of Integrated Traditional and Western Medicine, Jilin, Jilin Province; Jinzhong First People's Hospital, Jinzhong, Shanxi Province; Liaocheng People's Hospital, Liaocheng, Shandong Province; Liuzhou Red Cross Hospital, Liuzhou, Guangxi Province; Lixia District People's Hospital, Jinan, Shandong Province; Luohe No. 3 People's Hospital, Luohe, Henan Province; Luoyang No. 3 People's Hospital, Luoyang, Henan; Mianzhu People's Hospital, Mianzhu, Sichuan Province; The Hospital of Traditional Chinese Medicine of Sanmenxia, Sanmenxia, Henan Province; The People's Hospital of Hunan Province, Changsa, Hunan Province; The People's Hospital of Shaanxi Province, Xi'an, Shanxi Province; The Provincial Hospital of Shandong Province, Jinan, Shandong Province; The Second Hospital of Lanzhou, Lanzhou, Gansu Province; Xinxiang No. 1 People's Hospital, Xinxiang, Henan Province; Yangjiang Guangming Eye Hospital, Yangjiang, Guangdong Province; Yuncheng Eye Hospital, Yuncheong, Shanxi Province; Zhanjiang No. 2 People's Hospital, Zhanjiang, Guangdong Province; Zhaoging Minsheng Eye Hospital, Zhaoqing, Guangdong Province; Zhengzhou No. 2 People's Hospital, Zhengzhou, Henan Province. The Lifeline Express would like to thank the following Diabetic Retinopathy Assurance Centers for their contribution in the program (alphabetical order): Peking Union Medical College Hospital, Beijing; The Joint Shantou International Eye Center, Shantou; The Peking University Third Hospital, Beijing; Tongren Hospital, Beijing and Zhongshan Ophthalmic Center, Guangzhou.

Contributors NF founded the Lifeline Express and collected data. IYHW, MYN, GML designed the analytic plan. IYHW, MYN, IOLW, GML analysed and interpreted the data. MYN and IYHW wrote the first draft, and all authors contributed to revising the manuscript.

Funding The authors have not declared a specific grant for this research from any funding agency in the public, commercial or not-for-profit sectors.

Competing interests None declared.

Patient consent Not required.

Provenance and peer review Not commissioned; externally peer reviewed.

Data sharing statement № additional data is available.

Open access This is an open access article distributed in accordance with the Creative Commons Attribution Non Commercial (CC BY-NC 4.0) license, which permits others to distribute, remix, adapt, build upon this work non-commercially, and license their derivative works on different terms, provided the original work is properly cited, appropriate credit is given, any changes made indicated, and the use is non-commercial. See: http://creativecommons.org/licenses/by-nc/4.0/.

\section{REFERENCES}

1. Wang L, Gao P, Zhang M, et al. Prevalence and ethnic pattern of diabetes and prediabetes in China in 2013. JAMA 2017;317:2515-23.

2. Klein BE. Overview of epidemiologic studies of diabetic retinopathy. Ophthalmic Epidemiol 2007;14:179-83.

3. Frank RN. Diabetic retinopathy. N Engl J Med 2004;350:48-58. 
4. Cheung N, Wong IY, Wong TY. Ocular anti-VEGF therapy for diabetic retinopathy: overview of clinical efficacy and evolving applications. Diabetes Care 2014;37:900-5.

5. Wells JA, Glassman AR, Ayala AR, et al. Aflibercept, bevacizumab, or ranibizumab for diabetic macular edema. $N$ Engl J Med 2015;372:1193-203.

6. Prescott G, Sharp P, Goatman K, et al. Improving the costeffectiveness of photographic screening for diabetic macular oedema: a prospective, multi-centre, UK study. Br J Ophthalmol 2014;98:1042-9.

7. Rachapelle S, Legood R, Alavi Y, et al. The cost-utility of telemedicine to screen for diabetic retinopathy in India. Ophthalmology 2013;120:566-73.

8. Kawasaki R, Akune Y, Hiratsuka Y, et al. Cost-utility analysis of screening for diabetic retinopathy in Japan: a probabilistic Markov modeling study. Ophthalmic Epidemiol 2015;22:4-12.

9. Lian JX, Gangwani RA, McGhee SM, et al. Systematic screening for diabetic retinopathy (DR) in Hong Kong: prevalence of DR and visual impairment among diabetic population. $\mathrm{Br} J$ Ophthalmol 2016;100:151-5.

10. Thomas RL, Dunstan F, Luzio SD, et al. Incidence of diabetic retinopathy in people with type 2 diabetes mellitus attending the Diabetic Retinopathy Screening Service for Wales: retrospective analysis. BMJ 2012;344:e874.

11. Standards of medical care in diabetes-2015: summary of revisions. Diabetes care 2015;38(Suppl S4).

12. Blumenthal D, Hsiao W. Privatization and its discontents - the evolving Chinese health care system. N Engl J Med 2005:353:1165-70.

13. Yip WC, Hsiao WC, Chen W, et al. Early appraisal of China's huge and complex health-care reforms. Lancet 2012;379:833-42.

14. Cheng TM. Early results of China's historic health reforms: the view from minister Chen Zhu. Interview by Tsung-Mei Cheng. Health Aff 2012:31:2536-44.

15. Blumenthal D, Hsiao W. Lessons from the East-China's rapidly evolving health care system. N Engl J Med 2015;372:1281-5.

16. Ophthalmology ICo. Number of ophthalmologists in practice and training worldwide. 2018. http://www.icoph.org/ophthalmologistsworldwide.html

17. Harding S, Greenwood R, Aldington S, et al. Grading and disease management in national screening for diabetic retinopathy in England and Wales. Diabet Med 2003;20:965-71.

18. Mathers CD, Fat DM, Inoue M, et al. Counting the dead and what they died from: an assessment of the global status of cause of death data. Bull World Health Organ 2005;83:171-7.
19. Fleming S, Atherton H, McCartney D, et al. Self-screening and nonphysician screening for hypertension in communities: a systematic review. Am J Hypertens 2015;28:1316-24.

20. Keenum Z, McGwin G, Witherspoon CD, et al. Patients' adherence to recommended follow-up eye care after diabetic retinopathy screening in a publicly funded county clinic and factors associated with follow-up eye care use. JAMA Ophthalmol 2016;134:1221-8.

21. Mtuya C, Cleland CR, Philippin $\mathrm{H}$, et al. Reasons for poor follow-up of diabetic retinopathy patients after screening in Tanzania: a crosssectional study. BMC Ophthalmol 2016;16:115.

22. National Development and Reform Commission MoFA, and Ministry of Commerce of the People's Republic of China. Vision and actions on jointly building Silk Road Economic Belt and 21st century Maritime Silk Road. 2015. Chapters I-V (accessed 25 Jan 2018).

23. Hu R, Liu R, Hu N. China's Belt and Road Initiative from a global health perspective. Lancet Glob Health 2017;5:e752-e753.

24. Horton R. Offline: Are China's global ambitions good for global health? Lancet 2018;390:2752.

25. Commission NHaFP. NHFPC's implementation plan for the Belt and Road medical and health cooperation (2015-2017), 2015.

26. Tang K, Li Z, Li W, et al. China's Silk Road and global health. Lancet 2017;390:2595-601.

27. Wong TY, Cheung N, Tay WT, et al. Prevalence and risk factors for diabetic retinopathy: the Singapore Malay Eye Study. Ophthalmology 2008;115:1869-75.

28. Scanlon PH, Stratton IM, Leese GP, et al. Screening attendance, age group and diabetic retinopathy level at first screen. Diabet Med 2016;33:904-11.

29. Scotland G, McKeigue P, Philip S, et al. Modelling the costeffectiveness of adopting risk-stratified approaches to extended screening intervals in the national diabetic retinopathy screening programme in Scotland. Diabet Med 2016;33:886-95.

30. Xu Y, Wang L, He J, et al. Prevalence and control of diabetes in Chinese adults. JAMA 2013;310:948-59.

31. Andermann A, Blancquaert I, Beauchamp S, et al. Revisiting Wilson and Jungner in the genomic age: a review of screening criteria over the past 40 years. Bull World Health Organ 2008;86:317-9.

32. Center CINI. The 40th China Statistical Report on Internet Development. 2017. http://www.cnnic.net.cn/hlwfzyj/hlwxzbg/ hlwtjbg/201708/P020170807351923262153.pdf

33. Outline of the healthy China 2030 Plan (《“健康中国2030”规划 纲要》). 2016 http://www.gov.cn/zhengce/2016-10/25/content 5124174.htm (accessed 10 Jan 2017).

34. Mohamed Q, Gillies MC, Wong TY. Management of diabetic retinopathy: a systematic review. JAMA 2007;298:902-16. 